\title{
Gestão da cadeia de suprimento e vantagem competitiva: um modelo de análise a partir da teoria baseada em recursos
}

\section{Supply chain management and competitive advantage: an analisys model from resource based theory}

\author{
Fernando Luiz Emerenciano Viana ${ }^{1}$ \\ José de Paula Barros Neto ${ }^{2}$ \\ Miguel Eduardo Moreno Añez ${ }^{3}$
}

\section{Resumo}

A questão da vantagem competitiva vem sendo discutida sob diferentes visões, com grande inserção no campo teórico da estratégia empresarial. Entre as correntes explicativas da vantagem competitiva, encontra-se a teoria baseada em recursos, que explica a heterogeneidade das firmas e a vantagem competitiva a partir da configuração de seus recursos internos. Numa perspectiva ampliada, denominada de visão relacional, a vantagem competitiva pode estar associada à inserção da firma em redes de relacionamentos e ao desenvolvimento de recursos relacionais, sofrendo a influência do ambiente institucional. Por outro lado, a vantagem competitiva é muitas vezes atribuída às ferramentas de gestão utilizadas pelas organizações e às maneiras pelas quais as empresas conduzem suas unidades de negócios. Nesse contexto, a gestão da cadeia de suprimento (SCM - Supply Chain Management) surge como um importante elemento que pode favorecer a obtenção de vantagem competitiva por parte das empresas que seguem seus pressupostos. Entretanto, a área de SCM necessita de um melhor desenvolvimento teórico,

1 Doutor em Administração. Professor do Programa de Pós-Graduação em Administração da Universidade de Fortaleza (UNIFOR). Rua Dr. Correia Lima, 2150 Casa 10 - Sapiranga Fortaleza - CE. Fone: (85) 3258-1270; (85) 8765-1270. E-mail: fernandoviana@unifor.br

2 Doutor em Administração. Professor do Programa de Pós-Graduação em Administração e Controladoria (PPAC) da Universidade Federal do Ceará (UFC). Rua Coronel Jucá, 1612 Apto. 401, Torre II - Aldeota - Fortaleza - CE. Fone: (85) 3366-9600; Fax (85) 3366-9601. E-mail: jpbarros@ufc.br

3 Pós-Doutorado em Administração Internacional. Doutor em Administração. Professor Titular do Programa de Pós-Graduação em Administração da Universidade Federal do Rio Grande do Norte (PPGA/UFRN). Campus Universitário da UFRN - Ed. Goiabão do CCSA, Sala 7. CaixaPostal 1551 - Bairro Lagoa Nova - Natal/RN. CEP: 59073-000. Fone: (84) 3215-3513. E-mail: anez1957@yahoo.com.br 
especialmente com o uso de teorias organizacionais. Assim sendo, este trabalho tem como objetivo desenvolver um modelo de análise da contribuição da gestão da cadeia de suprimento para a obtenção de vantagem competitiva entre as empresas, com aplicação direcionada a cadeias de suprimento industriais, tendo como suporte teórico a teoria baseada em recursos, especialmente no que diz respeito à visão relacional. Trata-se de um ensaio teórico, no qual é apresentado um modelo de análise que pode ser aplicado em estudos empíricos futuros.

Palavras-chave: Gestão da Cadeia de Suprimento. Vantagem Competitiva. Teoria Baseada em Recursos.

\section{Abstract}

The quest of competitive advantage has being discussed from different visions with a large insertion on the theoretical business strategy field. This way, resource-based theory is one of the different explanatory streams of the competitive advantage that explains firm heterogeneity and competitive advantage based on the internal resources configuration. In an extended approach named relational view, the competitive advantage could be linked to the company insertion in networks and the relational resources development, also suffering the institutional environment influence. On the other hand the competitive advantage sometimes is associated with the use of managerial tools by the enterprises and how they conduct their businesses. In this scenario the Supply Chain Management (SCM) emerges like an important element that can help to competitive advantage attainment by the companies that use its bases. Nevertheless the field of SCM needs a better theoretical development, mainly by the use of organizational theories. Thus these paper intents to develop a supply chain management contribution to obtain competitive advantage analysis model to be applied on industrial supply chains, based on resource-based theory, specially the relational view. It is a theoretical essay work that presents an analysis model that could be applied in future empirical studies.

Keywords: Supply Chain Management. Competitive Advantage. Resource-based Theory.

\section{Introdução}

A questão da vantagem competitiva vem sendo discutida sob diferentes visões, com grande inserção no campo teórico da estratégia empresarial. De acordo com Vasconcelos e Cyrino (2000), as teorias da estratégia empresarial que tratam da questão da vantagem competitiva 
podem ser divididas em dois eixos principais. O primeiro eixo classifica os estudos segundo sua concepção de origem da vantagem competitiva, podendo ser dividido em duas correntes teóricas: (i) as teorias que consideram a vantagem competitiva como um atributo de posicionamento, exterior à organização, derivado da estrutura da indústria, da dinâmica da concorrência e do mercado; (ii) as teorias que consideram a performance superior como um fenômeno decorrente de características internas da organização. O segundo eixo discrimina as abordagens segundo suas premissas sobre a concorrência: (a) visão estrutural, essencialmente estática, da concorrência, fundada na noção de equilíbrio econômico; (b) visualização dos aspectos dinâmicos e mutáveis da concorrência, acentuando fenômenos como inovação, descontinuidade e desequilíbrio. Nesse contexto, as correntes explicativas da vantagem competitiva podem ser divididas em quatro grupos: (1) a análise estrutural da indústria; (2) a teoria dos recursos; (3) a escola austríaca (processos de mercado); e (4) a teoria das capacidades dinâmicas.

Os primeiros trabalhos sobre vantagem competitiva relacionados à teoria dos recursos surgiram, de certo modo, como um contraponto à visão estrutural da vantagem competitiva. Desde então, a teoria dos recursos vem evoluindo, sendo essa evolução marcada por uma extensão do foco nos recursos internos para uma visão mais abrangente, a qual considera a importância dos chamados recursos relacionais, bem como do ambiente institucional no qual as firmas estão inseridas, para a formação de vantagem competitiva. Desse modo, no presente trabalho, considera-se o escopo da teoria dos recursos, conforme definida por Acedo, Barroso e Gallan (2006), que a denomina teoria baseada em recursos (TBR) e subdivide esse campo teórico em três grupos que se complementam: a Visão Baseada em Recursos (RBV), a Visão Baseada em Conhecimento (KBV) e a Visão Relacional. Nesse sentido, utiliza-se a TBR como suporte teórico à análise da contribuição da gestão da cadeia de suprimento para a obtenção de vantagem competitiva, incluindo os três grupos de teorias supracitadas.

Ao mesmo tempo em que existem diferentes teorias que buscam explicar as possíveis fontes de obtenção de vantagem competitiva, tais 
como as detectadas anteriormente, a vantagem competitiva é muitas vezes atribuída às ferramentas de gestão utilizadas pelas organizações e às maneiras pelas quais as empresas conduzem suas unidades de negócios. Nesse contexto, a gestão da cadeira de suprimento (SCM Supply Chain Management) surge como um importante elemento que pode favorecer a obtenção de vantagem competitiva por parte das empresas que seguem seus pressupostos. Chen e Paulraj (2004), por exemplo, consideram que a adoção dos pressupostos do SCM tem impacto nos desempenhos das firmas envolvidas nas transações da cadeia de suprimento (fornecedores e compradores), o que pode trazer vantagem competitiva.

Segundo Miguel e Brito (2008), apesar de sua importância no mundo acadêmico e gerencial, a área de SCM ainda enfrenta dois desafios fundamentais. O primeiro refere-se ao desenvolvimento teórico, que continua em estágio inicial. O segundo diz respeito à ligação entre adoção de práticas e abordagem geral com desempenho superior, que carece de comprovação empírica mais ampla. No que diz respeito ao primeiro desafio, acredita-se que a utilização de teorias organizacionais como suporte teórico à gestão da cadeia de suprimento pode ajudar a suplantá-lo. Por outro lado, com relação ao segundo desafio, o desenvolvimento de modelos teóricos que permitam a realização de estudos que tragam maior comprovação empírica poderá contribuir para a inclusão de novos elementos e o fortalecimento do "núcleo" teórico do campo de conhecimento do SCM, considerando-se aqui o conceito de núcleo apresentado por Lakatos (1979).

Considerando-se o exposto, este trabalho tem como objetivo desenvolver um modelo de análise da contribuição do SCM para a obtenção de vantagem competitiva pelas empresas, tendo como suporte teórico a TBR, com ênfase na visão relacional (DYER; SINGH, 1998), com aplicação direcionada a cadeias de suprimento industriais.

A lógica à qual está vinculada a elaboração do modelo de análise é baseada nas seguintes considerações, cujas teorias que a subsidiam serão explicitadas nos seguintes tópicos: (1) embora existam correntes 
teóricas distintas explicativas da vantagem competitiva (VASCONCELOS; CYRINO, 2000), a vantagem competitiva baseada em recursos tem assumido um papel relevante nos estudos organizacionais; (2) a visão relacional (DYER; SINGH, 1998) constitui a parte da TBR (ACEDO; BARROSO; GALLAN, 2006) que destaca que as ligações exclusivas interfirmas podem ser uma fonte de ganhos relacionais e vantagem competitiva; (3) SCM é reconhecido como um elemento fundamental na busca de vantagem competitiva por parte das organizações que buscam a implementação desse conceito; (4) as relações interorganizacionais na cadeia de suprimento apresentam-se como um construto fundamental para o conceito de SCM (CHEN; PAULRAJ, 2004).

Considerando-se a lógica supracitada, para que seja possível o atendimento ao objetivo geral traçado, este artigo está estruturado em sete tópicos, incluindo o introdutório. No tópico 2 são apresentadas, de forma sucinta, as principais correntes teóricas ligadas à vantagem competitiva. O tópico 3 aborda a teoria baseada em recursos. No tópico 4, apresentase o SCM, incluindo os principais conceitos relacionados a essa temática. O tópico 5 relata algumas tipologias referentes aos relacionamentos interorganizacionais na cadeia de suprimento. No tópico 6 , discute-se a influência do ambiente institucional na vantagem competitiva. 0 tópico 7 apresenta o modelo de análise proposto, discutindo-se algumas de suas possíveis aplicações. Finalmente, o tópico 8 apresenta as considerações finais do trabalho.

\section{A questão da vantagem competitiva}

Observa-se que a questão da vantagem competitiva está no cerne do campo da estratégia empresarial, no qual se discute como as empresas devem se comportar para atingi-la e quais os fatores influenciam a obtenção de vantagem competitiva pelas organizações.

De acordo com Vasconcelos e Brito (2004), a vantagem competitiva pode ser vista como o objetivo das ações de uma empresa, podendo ser usada para explicar a diversidade entre as empresas, como meta da 
função corporativa e, por último, podendo explicar o sucesso ou fracasso na competição internacional.

Na visão de Porter (1986, 1989), uma firma adquire vantagem competitiva em dado mercado se obtiver um desempenho melhor do que seus competidores. A vantagem pode resultar de um menor curso de produção, da habilidade de prover a um grupo de clientes produtos ou serviços com maiores benefícios, ou ambos.

Segundo Barney e Hesterly (2007), uma empresa possui vantagem competitiva quando é capaz de gerar maior valor econômico do que as empresas rivais, sendo o valor econômico a diferença entre os benefícios percebidos ganhos por um cliente que compra produtos ou serviços de uma empresa e o custo econômico total desses produtos ou serviços. Desse modo, o tamanho da vantagem competitiva de uma empresa é a diferença entre o valor econômico que ela consegue gerar e o valor econômico gerado pelas suas rivais.

Observa-se que a relação entre vantagem competitiva e desempenho superior das firmas se apresenta como a visão dominante entre as diversas correntes que discutem esse conceito. Segundo Brito e Vasconcelos (2004), o conceito de vantagem competitiva surge como construto dominante na explicação dos motivos pelos quais algumas empresas apresentam desempenho superior.

Considerando as correntes teóricas ligadas à vantagem competitiva apresentadas por Vasconcelos e Cyrino (2000), citadas na seção 1, percebe-se que as duas que apresentam uma visão estática da concorrência (análise estrutural e teoria dos recursos) têm predominado. Assim sendo, o presente trabalho se restringe à discussão da contribuição delas.

Consoante Vasconcelos e Cyrino (2000), um dos modelos conceituais mais difundidos para a análise da vantagem competitiva é aquele da chamada nova organização industrial, configurando-se como um conjunto de ideias que se apoia nos trabalhos pioneiros de Edward Mason e Joe Bain sobre a estrutura da indústria. 
A vantagem competitiva surge fundamentalmente do valor que uma empresa consegue criar para seus compradores e que ultrapassa o custo de fabricação pela empresa. O valor é aquilo que os compradores estão dispostos a pagar, e o valor superior provém da oferta de preços mais baixos do que os da concorrência por benefícios equivalentes - vantagem competitiva com base em custo - ou do fornecimento de benefícios singulares que mais do que compensam um preço mais alto - vantagem competitiva com base em diferenciação (PORTER, 1989). A liderança em custo e a diferenciação são estratégias competitivas genéricas que potencialmente levam à vantagem competitiva.

Na análise de Porter (1986), a essência na formulação de uma estratégia competitiva e, por conseguinte, a busca por vantagem competitiva é relacionar uma firma ao seu meio ambiente, sendo o aspecto principal do meio ambiente de uma empresa a indústria ou as indústrias em que ela compete. A estrutura industrial tem uma forte influência na determinação das regras competitivas do jogo, assim como das estratégias potencialmente disponíveis para uma firma específica. As forças externas à indústria são significativas, principalmente em sentido relativo, já que, uma vez que as forças externas em geral afetam todas as empresas da indústria, o ponto básico encontra-se nas diferentes habilidades das empresas em lidar com elas.

Seguindo a mesma linha de pensamento, que aborda a questão da vantagem competitiva com a ênfase da análise estrutural da indústria e no ambiente externo, Ghemawat (1986) propõe que as fontes estruturais da vantagem competitiva podem ser encontradas em fatores ligados à inovação do produto, a processos de produção ou às capacidades de marketing das empresas. Em suas análises, Ghemawat (1986) detalha essas características genéricas em outras mais específicas, destacando que as vantagens competitivas podem decorrer de três categorias: benefícios do tamanho (economias de escala, curvas de experiência ou economias de escopo), vantagens de acesso privilegiado a recursos ou a clientes (know-how, matérias-primas e mercados), bem como do exercício de opções que garantam flexibilidade estratégica. Vale ressaltar que essas categorias que podem trazer vantagem competitiva 
não são mutuamente exclusivas; elas podem e devem interagir. Quanto mais delas ocorrerem simultaneamente, melhor.

Uma segunda corrente teórica sobre vantagem competitiva, que possui uma visão estática da concorrência, é a chamada teoria dos recursos, cujos primeiros trabalhos surgiram, de modo geral, como um contraponto à visão estrutural da vantagem competitiva.

Segundo Caves (1984), uma estratégia pode levar à vantagem competitiva por dois motivos principais: ou porque leva a um monopólio natural, pelo desenvolvimento de recursos escassos únicos, ou porque a sua implementação de forma hábil por um limitado número de firmas torna a sua replicação inútil para as firmas retardatárias.

Nessa mesma linha de pensamento, Barney (1991) considera que uma firma possui vantagem competitiva quando implementa uma estratégia de criação de valor que não está sendo implementada simultaneamente por qualquer competidor atual ou potencial. Essa vantagem competitiva é dita sustentável quando isso acontece e, também, quando as outras firmas são incapazes de replicar os benefícios dessa estratégia. Ademais, a busca por fontes de vantagem competitiva sustentável deve focar sobre a heterogeneidade e a imobilidade dos recursos da firma. Existem quatro atributos que um recurso deve possuir para se constituir uma fonte potencial de vantagem competitiva: (a) deve ser valioso; (b) deve ser raro entre os competidores da firma; (c) deve ser imperfeitamente imitável; e (d) não existem recursos substitutos com as três características anteriores.

De acordo com Peteraf (1993), a heterogeneidade dos recursos das firmas tem relação direta com a possibilidade de obtenção de ganhos acima dos normais por parte destas e, consequentemente, com a obtenção de vantagem competitiva. Uma grande contribuição da teoria dos recursos é que ela explica diferenças de longo prazo na lucratividade da firma que não podem ser atribuídas a diferenças nas condições da indústria, nem são explicadas pela participação da firma na indústria. 
Quando se analisam as duas principais correntes teóricas acerca da vantagem competitiva supracitadas, percebe-se uma diferença fundamental entre elas: a unidade de análise. Enquanto a análise estrutural da indústria tem como unidade de análise a indústria ou setor econômico, a teoria dos recursos tem como unidade de análise as firmas individuais ou as unidades de negócio. Ademais, correntes teóricas mais recentes que estão inseridas na teoria dos recursos, como a visão relacional (DYER; SINGH, 1998), ultrapassam as fronteiras da firma ao considerarem as relações entre firmas (relações interorganizacionais) como unidade de análise.

Essa discussão acerca dos fatores explicativos da vantagem competitiva tem evoluído, especialmente com a possibilidade de uso de técnicas quantitativas, que permitiram o desenvolvimento de modelos que consideram diversas variáveis que podem contribuir para a obtenção de desempenho superior e, consequentemente, vantagem competitiva.

A consideração de que a dispersão do desempenho das empresas pode ser associada a vários fatores forma a base da chamada técnica de componentes de variância. De acordo com Vasconcelos e Brito (2004), o desempenho individual de uma empresa, dentro de uma população de outras empresas, pode ser concebido como influenciado por vários grupos de fatores. O uso da técnica de componentes de variância permite, então, avaliar qual o percentual da variância total pode ser atribuído a cada grupo de fatores.

Entre os estudos que analisaram a contribuição de diversos fatores para a dispersão do desempenho das empresas, com o uso de modelos baseados na técnica de componentes de variância, os trabalhos de Schmalensee (1985) e Rumelt (1991) utilizaram dados do setor industrial e relataram resultados conflitantes, já que Schmalensee (1985) atribui ao setor (indústria) o papel mais relevante na diferenciação do desempenho relativo entre as empresas, em linha com a visão estrutural, enquanto Rumelt (1991) atribui aos recursos ou posicionamento no mercado, que são fatores específicos da unidade de negócio, a heterogeneidade de desempenho entre as firmas, em linha com os argumentos da 
visão dos recursos. Por sua vez, McGahan e Porter (1997) utilizaram dados de empresas de setores diversos, incluindo empresas de serviços, apresentando resultados mais consistentes com o estudo de Schmalensee (1985), reforçando a importância da estrutura da indústria para a heterogeneidade de desempenho e, de certa forma, questionando Rumelt (1991), embora destaque as diferenças existentes nas bases de dados utilizadas.

Percebe-se que os estudos de componentes de variância diferem principalmente em relação à influência da indústria na heterogeneidade de desempenho, mas, em geral, mostram que os fatores específicos da firma têm uma contribuição percentual mais importante. Assim sendo, Vasconcelos e Brito (2004) afirmam que eles apresentam resultados razoavelmente consistentes, especialmente quando são analisadas apenas empresas de manufatura, levando a um consenso de que a vantagem competitiva é específica a cada empresa (unidade de negócio). Nesse sentido, a vantagem competitiva pode ser concebida como a influência líquida de todos os fatores idiossincráticos da empresa sobre o seu desempenho durante um período determinado, excluindo-se a influência de outros fatores, como a indústria, os fatores temporais e o erro estatístico; essa é a chamada vantagem competitiva resultante. Além dos fatores idiossincráticos da firma, podem existir fatores isolados associados de forma única à empresa e que influenciam seu desempenho, o que podem trazer a denominada vantagem competitiva componente (VASCONCELOS; BRITO, 2004), bem como nos casos em que a influência é negativa, podem constituir uma desvantagem competitiva (componente). A vantagem competitiva resultante seria, então, o resultado final de todas as influências idiossincráticas da empresa sobre o seu resultado, sejam elas positivas ou negativas, bem como os efeitos das interações.

Apesar de se conseguir estabelecer várias diferenças nas abordagens oferecidas pelas correntes explicativas da vantagem competitiva, percebe-se que não se deve tratá-las de modo isolado, pois elas apresentam complementariedades importantes. No contexto deste trabalho, entende-se que a vantagem competitiva pode derivar tanto 
de recursos e competências únicas de uma firma específica como da posição específica e protegida da estrutura de mercado, corroborando com a visão de Cool, Costa e Dierickx (2002). Na verdade, assume-se que, além dos recursos e competências internas da firma, os recursos e competências utilizados e/ou derivados das relações interorganizacionais da firma também podem se constituir em fonte de obtenção de vantagem competitiva, incluindo-se nessas relações as existentes entre uma firma e alguns componentes de seu ambiente institucional. Ademais, as firmas devem estar atentas às necessidades de reconfigurações de seus recursos e posicionamentos para a manutenção da vantagem competitiva. Desse modo, estabelece-se uma discussão teórica mais aprofundada sobre a teoria baseada em recursos no tópico 3; no tópico 6 , são contempladas as questões relativas à influência do ambiente institucional na vantagem competitiva.

\section{Teoria baseada em recursos}

Observa-se que a visualização dos recursos da firma como elementos fundamentais para sua vantagem competitiva e o surgimento do campo teórico da teoria baseada em recursos podem ser associados ao trabalho de Wernerfelt (1984). Desde então, a teoria baseada em recursos vem evoluindo e se constituindo em um campo teórico marcante para os estudos sobre vantagem competitiva. Essa evolução foi marcada por uma extensão do foco nos recursos internos para uma visão mais abrangente, a qual considera a importância dos chamados recursos relacionais e do ambiente institucional no qual as firmas estão inseridas, para a formação de vantagem competitiva. Desse modo, será considerado neste trabalho o escopo da teoria baseada em recursos, conforme definida por Acedo, Barroso e Gallan (2006).

A visão baseada em recursos (RBV) aborda as vantagens competitivas relacionadas com a posse da firma de recursos heterogêneos (financeiros, físicos, humanos, tecnológicos, organizacionais e de reputação) e habilidades propiciadas pela combinação de dois ou mais recursos (GRANT, 1991). De acordo com os pressupostos da 
RBV, a compra e a acumulação de recursos tornam-se necessidades estratégicas. Diferentemente da ênfase tradicional externa, a visão baseada em recursos enfatiza os aspectos internos da firma.

Tendo-se em mente os conceitos fundamentais ligados à RBV e a dinamicidade do ambiente competitivo contemporâneo, percebe-se uma evolução nas abordagens relacionadas à competição baseada em recursos, para adequar os pressupostos teóricos às mudanças organizacionais necessárias à manutenção da vantagem competitiva nos diversos níveis de análise. Entre essas mudanças, destaca-se o papel relevante do conhecimento como elemento de vantagem competitiva.

$\mathrm{Na}$ análise de Grant (1996), a visão baseada em conhecimento (knowledge-based view - KBV) considera o conhecimento como o mais estrategicamente importante recurso da firma, portanto, podendo ser considerada uma consequência da RBV. As questões com as quais a KBV preocupa-se estão além dos interesses tradicionais da gestão estratégica, direcionando-se para alguns outros interesses fundamentais da teoria da firma, notadamente a natureza da coordenação dentro da firma, a estrutura organizacional, o papel do gerenciamento e da alocação dos direitos da tomada de decisão, os determinantes dos limites da firma e a teoria da inovação.

De acordo com Kogut e Zander (1992), o foco teórico deve ser direcionado ao entendimento da base de conhecimento da firma que conduz a um conjunto de capacidades que aumentam as chances de crescimento e sobrevivência. Nesse sentido, Grant (1996) destaca que a literatura sobre análise e gestão do conhecimento aponta para as seguintes características como pertinentes para a utilização do conhecimento dentro da firma para criar valor: possibilidade de transferência (transferability), capacidade para agregação (que é maior quando o conhecimento pode ser expresso numa linguagem comum), apropriabilidade (habilidade do possuidor do recurso receber um retorno igual ao valor criado pelo recurso), especialização na aquisição do conhecimento e relevância do conhecimento como insumo para a produção. 
Na perspectiva mais ampla da gestão da cadeia de suprimento, o conhecimento da firma consiste também na informação sobre outros atores da cadeia, bem como sobre os procedimentos pelos quais os recursos são adquiridos e as transações e a cooperação são conduzidas. Para tal, mostra-se relevante a utilização de uma visão com foco nos relacionamentos da firma com os componentes da cadeia de suprimento, o que é propiciada pela visão relacional.

Tendo como referência as duas visões preponderantes em relação às fontes de retornos acima do normal e à vantagem competitiva, Dyer e Singh (1998) consideram que elas ignoram o fato de que as vantagens ou desvantagens de uma firma individual são frequentemente ligadas às vantagens e desvantagens das redes de relacionamentos nas quais a firma está imersa, e que os recursos críticos de uma firma podem se estender além das fronteiras desta. Desse modo, as ligações exclusivas interfirmas podem ser uma fonte de ganhos relacionais e vantagem competitiva. Assim sendo, Dyer e Singh (1998) apresentam a visão relacional da vantagem competitiva, que tem o foco sobre as rotinas e processos diádicos ou de rede como uma importante unidade de análise para o entendimento da vantagem competitiva.

Define-se um ganho relacional como um lucro acima do normal conjuntamente gerado em um relacionamento de troca que não pode ser gerado por qualquer firma de modo isolado, podendo ser criado somente através de contribuições conjuntas exclusivas dos parceiros específicos de uma aliança (DYER; SINGH, 1998). De modo resumido, as quatro fontes de ganhos relacionais são: (1) investimentos em ativos específicos para a relação; (2) troca substancial de conhecimento, incluindo a troca de conhecimento que resulta em aprendizagem conjunta; (3) combinação de recursos e capacidades ou habilidades complementares, porém escassos, que resultam na criação conjunta de novos produtos, serviços ou tecnologias únicas; e (4) baixos custos de transação em relação a alianças competidoras, devido a mecanismos de governança mais efetivos. 
Percebe-se que as bases teóricas da visão relacional, embora incorporem elementos da visão baseada em recursos e da visão baseada em conhecimentos, tendo em vista o foco na explicação das fontes de heterogeneidade entre as firmas, formaram-se a partir dos estudos realizados por Jeffrey Dyer para comparar empresas da indústria automobilística do Japão e dos Estados Unidos (DYER, 1996; DYER, 1997), no que diz respeito ao relacionamento das montadoras com os seus fornecedores.

De acordo com Dyer (1996), existe uma relação positiva entre os investimentos na especialização de ativos interfirmas e o desempenho da rede de produção, que pode ser considerada a cadeia de suprimento da qual a firma faz parte. Entretanto, os investimentos específicos das transações parecem resultar em vantagem competitiva quando: (1) as firmas envolvidas na transação desenvolvem salvaguardas que podem controlar o oportunismo com custos relativamente baixos; e (2) as atividades realizadas ao longo da cadeia de suprimento são caracterizadas por um alto grau de interdependência.

Ademais, Dyer (1996) ressalta existirem condições limitantes que podem influenciar a eficácia dos investimentos específicos da transação como uma fonte de vantagem competitiva: (i) o ambiente institucional e contratual; (ii) o nível de volatilidade e incerteza do setor e; (iii) a interdependência entre tarefas e produtos ao longo da cadeia de suprimento. Pela análise das duas primeiras considerações, percebese a relevância de se avaliar as condições do ambiente institucional (externo) quando se analisa a questão da vantagem competitiva.

Além da preocupação inerente à obtenção de ganhos relacionais, a visão relacional também destaca a importância de que sejam buscados mecanismos que preservem os ganhos relacionais. Somados aos mecanismos relacionados às características que tornam os recursos imperfeitamente imitáveis, de acordo com os argumentos já apresentados de Barney (1991), Dyer e Singh (1998) destacam os seguintes mecanismos: (a) interconectividade dos ativos interorganizacionais; (b) escassez do parceiro; (c) indivisibilidade do recurso e; (d) ambiente institucional. 
Percebe-se que, ao levar em conta o mecanismo denominado ambiente institucional, a teoria baseada em recursos avança no sentido de, pelo menos indiretamente, considerar o papel do ambiente na formação de vantagem competitiva sustentável. De certo modo, esse fato contempla o argumento defendido por Oliver (1996), segundo o qual os impedimentos institucionais para a atividade econômica são determinantes da heterogeneidade das firmas, que se origina no ambiente institucional. Na mesma linha de pensamento, Dyer (1997) considera o ambiente institucional uma das condições limitantes que podem influenciar a eficácia dos investimentos específicos da transação como uma fonte de vantagem competitiva. Considerando-se o exposto, destaca-se no tópico 6 a influência do ambiente institucional na vantagem competitiva.

\section{A gestão da cadeia de suprimento}

O debate acerca da cadeia de suprimento tem assumido, ao longo dos últimos anos, um papel relevante nas discussões acadêmicas e de cunho prático relacionadas à gestão organizacional. De acordo com Cousins, Lawson e Squire (2006), nos últimos vinte anos, o SCM tem recebido elevada atenção de estudiosos de uma variedade de disciplinas acadêmicas que têm contribuído para o aprofundamento do conhecimento e do desenvolvimento teórico desta temática. Entretanto, parece haver pouco consenso acerca das bases conceituais e de metodologia de pesquisa do SCM, deixando lacunas na base de conhecimento desse campo (BURGESS; SINGH; KOROGLU, 2006). Desse modo, tornase importante discutir os diversos conceitos presentes na literatura, buscando-se a adoção de um conceito único a ser seguido.

De acordo com Lambert, Cooper e Pagh (1998), um conceito adequado de gestão da cadeia de suprimento é aquele desenvolvido em 1994 e modificado em 1998 pelos participantes do Fórum Global de Cadeia de Suprimento: SCM é a integração de processos-chave de negócios do usuário final até os fornecedores originais, que provêem produtos, serviços e informações que adicionam valor para os consumidores e outros stakeholders. 
Mentzer et al. (2001) examinaram o fenômeno do SCM com maior atenção, buscando definir claramente o termo e o conceito, de modo a identificar os fatores que contribuem para uma efetiva gestão da cadeia de suprimento, além de sugerir como a adoção de uma abordagem de SCM pode afetar a estratégia corporativa e a performance. Considerando as diferentes visões do SCM, Mentzer et al. (2001) chegam a uma definição bastante abrangente, na qual a gestão da cadeia de suprimento é considerada uma coordenação sistemática e estratégica das tradicionais funções dos negócios e das táticas entre essas funções, dentro de uma empresa particular e entre as firmas de uma cadeia de suprimento, com o propósito de melhorar a performance de longo prazo das firmas individuais e da cadeia de suprimento como um todo. É importante ressaltar que a coordenação interfuncional inclui o exame dos papéis da confiança, comprometimento, risco e dependência da viabilidade da coordenação e do compartilhamento funcionais internos. Por outro lado, a coordenação interfirmas inclui mudanças funcionais dentro da cadeia de suprimento, o papel dos vários tipos de provedores de serviços terceirizados, como os relacionamentos entre empresas devem ser gerenciados, e a viabilidade de diferentes estruturas de cadeia de suprimento.

As diferentes maneiras pelas quais o SCM é conceitualmente formado foi também objeto de investigação de Burgess, Singh e Koroglu (2006), que identificaram quatro categorias diferentes: atividade (incluindo os casos em que o SCM foi descrito como uma função individual de um processo); processo (cadeia de atividades relacionadas); sistema (séries de processos relacionados; coleção de conceitos imprecisamente conectados; redes); e outros (um profundo nível de análise que inclui conceitos psicológicos, sociológicos e filosóficos). Essas quatro categorias podem ser vistas como uma escala que vai da perspectiva "micro" para a "macro".

Analisando-se as definições supracitadas, torna-se relevante tecer alguns comentários. Em primeiro lugar, a definição de gestão da cadeia de suprimento, que inicialmente era fortemente associada à função logística, apresenta um escopo ampliado, incluindo todas as funções intra 
e interfirmas que contribuem para a agregação de valor ao consumidor final. Desse modo, fica claro o papel estratégico da gestão da cadeia de suprimento e a necessidade de coordenação interfuncional e interfirmas. Em segundo lugar, é mostrado que um dos principais objetivos da gestão da cadeia de suprimento, ao adicionar valor ao cliente e satisfazê-lo, é propiciar vantagem competitiva das firmas individuais e da cadeia como um todo. Assim sendo, ressalta-se a necessidade de se estabelecer ligações entre teorias sobre vantagem competitiva e SCM, o que constitui o objetivo desse trabalho. Por último, percebe-se uma visão ampliada da cadeia de suprimento, ressaltando a importância de se visualizar o papel dos provedores de serviços terceirizados, bem como da estruturação de relacionamentos interorganizacionais condizentes com as necessidades e objetivos da cadeia de suprimento.

Estando cientes de que, quando se pretende avançar na construção da base conceitual de um campo de estudo, é importante que os diferentes conceitos sejam agrupados em construtos, Chen e Paulraj (2004) desenvolveram um modelo de pesquisa para o SCM, com o objetivo de contribuir para o desenvolvimento de construtos de SCM, a partir de um conjunto inicial de medidas operacionais. Nesse modelo, o principal elemento utilizado por Chen e Paulraj (2004) para caracterizar o SCM é constituído pelas relações entre compradores e fornecedores, que, por sua vez, podem ser representadas por cinco construtos:

- Redução da base de fornecedores $\rightarrow$ Esse construto inclui indicadores relacionados à quantidade (reduzida) de fornecedores.

- Relações de longo prazo $\rightarrow$ Construto operacionalizado para envolver as iniciativas tomadas pelas firmas compradoras a fim de encorajar o estabelecimento de relacionamentos de longo prazo com os fornecedores.

- Comunicação $\rightarrow$ Esse construto pressupõe fluxos de comunicação e interação nos dois sentidos entre compradores e fornecedores.

- Equipes interfuncionais $\rightarrow$ Construto operacionalizado para 
definir os esforços realizados para utilizar equipes do comprador envolvidas com o fornecedor.

- Envolvimento do fornecedor $\rightarrow$ Construto baseado no envolvimento do fornecedor nos processos de projeto e planejamento.

Considerando-se a importância das relações interorganizacionais na cadeia de suprimento para a caracterização do SCM, conforme estabelecido por Chen e Paulraj (2004), no tópico seguinte, são discutidas algumas questões e tipologias inerentes aos relacionamentos interorganizacionais.

\section{Relações interorganizacionais na cadeia de suprimento}

Quando se busca compreender, entre outras questões, como a gestão da cadeia de suprimento contribui para a obtenção de vantagem competitiva, entende-se que é pertinente qualificar, a partir da visão de alguns autores, os diferentes tipos de relacionamentos interfirmas que podem ocorrer no âmbito da cadeia de suprimento.

Uma das mais importantes contribuições para a compreensão das diferentes estruturas de relações interorganizacionais foi introduzida pela teoria dos custos de transação (WILLIAMSON, 1975, 1989), que considera como unidade de análise relevante para os estudos organizacionais as transações entre firmas. A teoria dos custos de transação (TCT) tem como fundamentos básicos a atuação dos agentes econômicos de acordo com seus interesses particulares, a existência de oportunismo, malícia e desonestidade nas relações, bem como a racionalidade limitada dos indivíduos. Ademais, Williamson (1989) considera que a dimensão mais decisiva para a descrição das transações é a especificidade dos ativos nelas envolvidas. De início, a TCT levantou os principais aspectos positivos e negativos da realização das transações no mercado ou pela própria firma (hierarquia), tendo como referência os custos de transação associados a cada uma das alternativas, consideradas, então, como dicotômicas. Os custos de transação constituem os custos necessários 
ao estabelecimento de salvaguardas, incluindo custos de negociação, custos de união, custos de monitoramento e custos de coerção (HILL, 1990).

Tendo em vista a visão dicotômica entre mercado e hierarquia, postulada inicialmente pela teoria dos custos de transação, surgiram algumas críticas, tais como as elaboradas por Hill (1990), que considera que a TCT foi negligente em relação às implicações que um contexto ampliado tem sobre os riscos do oportunismo, que constitui um elemento chave, assim como a racionalidade limitada e a especificidade dos ativos, para os pressupostos da TCT. Hill (1990) inclui no chamado contexto ampliado: (a) o contexto social dentro do qual as transações econômicas são realizadas e; (b) o mecanismo denominado "mão invisível do mercado". Nessa perspectiva, ao longo do tempo a "mão invisível do mercado" favorece os atores que tendem a atuar de forma cooperativa, em vez de oportunista. Desse modo, quando o estado de equilíbrio competitivo é atingido, a população de atores econômicos (que estão envolvidos em transações) contém somente aqueles cujos repertórios de comportamento são marcados pela cooperação. Assim sendo, a reputação torna-se uma característica importante para os atores econômicos.

Ciente das limitações presentes nas suas primeiras publicações acerca da teoria dos custos de transação, Williamson (1991) relata que, em regimes nos quais os efeitos da reputação interfirmas são altamente aperfeiçoados, a solução dicotômica entre mercado e hierarquia não é suficiente. Então, Williamson (1991) apresenta a estrutura de governança híbrida, que possui características intermediárias entre os polos mercado e hierarquia. Ademais, Williamson (1991) ressalta que as características que devem ser levadas em consideração para a caracterização das diferentes estruturas de governança são o regime de contrato (contract law), o mecanismo de adaptabilidade (autonomia, coordenação) e os instrumentos de incentivo e controle das transações.

Corroborando a sua intenção de absorver algumas das críticas dirigidas aos seus trabalhos anteriores, Williamson (2002) reconhece a 
existência de uma transformação fundamental ocorrida nas transações econômicas. Essa transformação fundamental refere-se às seguintes mudanças no padrão das transações: (i) diminuição do número de fornecedores com os quais uma empresa realiza suas transações no mercado; (ii) as transações genéricas (compradores e vendedores anônimos) dão lugar às transações em que a identidade das partes importa, nas quais a continuidade da relação possui consequências de custo significativas. Desse modo, as transações nas quais há uma condição de dependência bilateral são aquelas para as quais a transformação fundamental ocorreu, sendo que um fator chave a ser analisado nessas transações é se estão presentes investimentos em ativos específicos.

Para dar conta da transformação fundamental ocorrida, os estudos acerca dos possíveis modos de se estruturar as transações das firmas evoluíram, dando origem a um campo de estudo denominado por Williamson (2005) como economia da governança. A economia da governança faz a distinção entre três estruturas de governança básicas: mercados clássicos (trocas simples em mercados spot), estruturas híbridas (contratos de longo prazo) e hierarquias. As característicaschaves da governança (intensidade de incentivos diferenciais, controle administrativo e regime de contrato) são postuladas para variar de forma consistente entre modos alternativos. Diferentes combinações de atributos trazem forças e fraquezas adaptativas distintas. O Quadro 1 apresenta as principais características das diferentes estruturas de governança apresentadas por Williamson (1991): 
Quadro 1 - Principais características das diferentes estruturas de governança postuladas por Williamsom (1991)

\begin{tabular}{|c|c|c|c|c|}
\hline $\begin{array}{l}\text { Estrutura de } \\
\text { Governança }\end{array}$ & $\begin{array}{l}\text { Intensidade } \\
\text { de Incentivos }\end{array}$ & $\begin{array}{c}\text { Controle } \\
\text { Administrativo }\end{array}$ & $\begin{array}{c}\text { Regime de } \\
\text { Contrato }\end{array}$ & Observações \\
\hline Mercado & Alta & Baixo & Regras legais & $\begin{array}{c}\text { Favorece a } \\
\text { adaptação, dificulta } \\
\text { a cooperação }\end{array}$ \\
\hline Híbrida & Média & Médio & Compromisso & $\begin{array}{c}\text { Favorece relações } \\
\text { de longo prazo } \\
\text { entre as firmas }\end{array}$ \\
\hline Hierarquia & Baixa & Alto & $\begin{array}{l}\text { Contrato de } \\
\text { trabalho }\end{array}$ & $\begin{array}{c}\text { Dificulta a } \\
\text { adaptação, } \\
\text { favorece a } \\
\text { cooperação }\end{array}$ \\
\hline
\end{tabular}

Fonte: Elaboração dos autores.

A estrutura de governança híbrida é, em algumas situações, considerada uma das formas de estruturação das redes de relações interorganizacionais. Para Thorelli (1986), o termo redes se refere a duas ou mais organizações envolvidas em relacionamentos de longo prazo. A rede pode ser vista como uma alternativa para a integração vertical (hierarquia) e para a diversificação (mercado). O engajamento em uma rede pode reduzir os riscos relativos a ambas as situações, participação em mercados spot e total integração.

Uma argumentação adicional relacionada aos relacionamentos interorganizacionais e às suas formações é apresentada por Oliver (1990), que conceitua os relacionamentos interorganizacionais (RIOs) como as transações, fluxos e ligações relativamente duradouros (ou permanentes) entre uma organização e uma ou mais organizações de seu ambiente. As condições sob as quais se formam os relacionamentos referem-se aos fatores ambientais e interorganizacionais que aumentam a probabilidade de que diferentes contingências causem a ocorrência dos RIOs.

Voltando-se à questão das três estruturas de governança preconizadas por Williamson (1991), percebe-se que a estrutura de governança híbrida, a qual ressalta o papel do comprometimento entre as firmas que realizam a transação, bem como pressupõe o 
estabelecimento de relacionamentos de longo prazo, possui algumas características condizentes com a tipologia de relacionamentos interorganizacionais que vieram à tona a partir de estudos realizados na indústria automobilística japonesa, os quais têm sido alvo de um grande número de investigações empíricas, sendo comumente denominados relacionamentos colaborativos ou em regime de parceria, embora muitos dos atributos desse tipo de relacionamento, especialmente a confiança dos parceiros com os quais são realizadas as transações, não estejam contemplados nos trabalhos de Williamson (1975, 1989, 1991, 1996, 2002, 2005).

Devido ao crescente entendimento da importância da confiança para o estabelecimento e a manutenção de relacionamentos interfirmas duradouros, o papel desse construto nas transações interfirmas tem sido considerado por autores das diversas correntes de teorias organizacionais.

Barney e Hansen (1994), por exemplo, avaliam o papel da confiança entre os parceiros de uma transação como fonte de vantagem competitiva. Para tal, adotam o conceito de confiança como uma crença mútua de que nenhuma das partes de uma transação explorará as possíveis vulnerabilidades da outra parte. Já Uzzi (1997) visualiza a confiança expressa como uma crença que um parceiro de troca não age com interesse próprio e operaria não como um risco calculado, mas de modo heurístico. Os dois conceitos apresentados, apesar de possuírem certa similaridade, são diferentes, já que Barney e Hansen (1994) consideram a confiança como algo que emerge porque atores racionais, pensando no interesse próprio, não devem se comportar de modo oportunista, tanto por razões econômicas, como por razões sociais. É importante ressaltar que, no presente trabalho, não se tem como objetivo discutir com maior propriedade as características ou tipos de confianças que emergem nas relações interorganizacionais, e sim considerar a confiança como algo que pode influenciar a natureza dos relacionamentos interorganizacionais que são estabelecidos numa cadeia de suprimento, juntamente com outros elementos relevantes para tal. 
Observa-se que a adoção de diferentes tipos de relacionamentos entre firmas de uma cadeia de suprimento constitui um elemento diretamente relacionado com as diferenças de desempenho entre empresas. Na visão de Dyer (1996), uma importante dimensão sobre a qual as firmas diferem é a extensão da especialização interorganizacional. O desempenho de uma firma está ligado à extensão pela qual ela e seus fornecedores realizam investimentos em ativos específicos, sejam estes ativos físicos, humanos ou de localização (site). As firmas podem obter vantagem competitiva quando elas desenvolvem uma rede de produção fortemente integrada, caracterizada por um alto grau de especialização interfirmas. Uma firma pode buscar vantagens de eficiência criando ativos que são especializados em conjunção com os ativos de um parceiro de negócios (DYER, 1996). Embora Dyer (1996) considere a especificidade de ativos um elemento central para a análise de relacionamentos interfirmas, corroborando com os pressupostos de Williamson (1991), esses dois autores discordam em um ponto chave: enquanto Williamson (1991) relata que o aumento na especificidade de ativos de uma relação interorganizacional leva a um aumento dos custos de transação, Dyer (1996) acredita que a especificidade de ativos leva a uma diminuição dos custos de transação.

Um argumento defendido por Dyer, Cho e Chu (1998) é o de que as firmas devem pensar de modo estratégico as suas relações na cadeia de suprimento, especialmente no que diz respeito à gestão de fornecedores, de modo a não ter uma estratégia única. Cada fornecedor deve ser analisado estrategicamente para se determinar a extensão pela qual o produto do fornecedor contribui para as competências chaves e a vantagem competitiva da firma compradora. A habilidade de uma empresa para segmentar de forma estratégica os fornecedores, de modo a obter os benefícios dos possíveis tipos de relacionamentos, provê a chave para a vantagem competitiva futura na gestão da cadeia de suprimento.

Assim sendo, Dyer, Cho e Chu (1998) apresentam, com base em estudos realizados na indústria automobilística dos Estados Unidos, Japão e Coreia do Sul, três possíveis regimes de relações interorganizacionais 
na cadeia de suprimento, com as suas características principais: regime arm's length (mercado), regime de parceria e regime de quase-mercado.

\section{Regime arm's length (mercado)}

Constitui uma visão tradicional, a qual advoga a minimização da dependência em relação aos fornecedores e a maximização do poder de barganha. Nesse regime, busca-se evitar qualquer forma de comprometimento (DYER; CHO; CHU, 1998)

De acordo com Bronzo (2004), no arm's length, não existem incentivos econômicos ou organizacionais suficientes para que a confiança entre os agentes econômicos seja incrementada em uma base contínua, sustentada no longo prazo. Geralmente, as transações econômicas são acompanhadas por mecanismos mais formais de salvaguardas. Os objetivos do relacionamento voltam-se mais para questões de eficiência do que para economias de aprendizagem, tendo como reflexo a tendência do estabelecimento de contratos de curto prazo baseados em especificações detalhadas.

Geralmente, em um regime arm's length, o envolvimento dos fornecedores não é antecipado no processo de suprimento, sendo menores a frequência e o conteúdo da troca de informações entre os agentes, em função do baixo valor agregado ou do baixo conteúdo tecnológico dos bens transacionados, ou devido às situações em que as compras referem-se a materiais indiretos (BRONZO, 2004).

\section{Regime de parceria}

O regime de parceria se contrapõe em várias características ao regime de arm's length. De acordo com Dyer, Cho e Chu (1998), há nesse regime uma maior troca de informações e uma melhor coordenação entre tarefas interdependentes; há investimento em ativos dedicados ou específicos da relação; a confiança é o principal mecanismo de governança.

As parcerias estratégicas são necessárias quando se trata do fornecimento de insumos estratégicos, ou seja, aqueles que tipicamente adicionam valor e representam um importante papel na diferenciação do 
produto final do comprador. As parcerias estratégicas requerem múltiplas interfaces entre funções do comprador e do fornecedor. Ademais, investimentos específicos da relação são necessários para que haja uma coordenação efetiva entre as firmas envolvidas na transação, incluindo investimentos em plantas e equipamentos dedicados, pessoal dedicado e processos de manufatura integrados (DYER; CHO; CHU, 1998).

$\mathrm{Na}$ análise de Bronzo (2004), a segmentação em regime de parceria difere do regime arm's length por várias razões, entre as quais se destacam: (i) redução drástica do número de fornecedores e estabelecimento de contratos de prazo mais longo; (ii) fluxo robusto de informações estratégicas e melhor coordenação interorganizacional; (iii) incentivos para o incremento dos investimentos específicos em ativos físicos, humanos e de localização; (iv) níveis superiores de serviço em âmbito logístico; (v) maior velocidade no desenvolvimento de novos produtos; (vi) as relações de cooperação e confiança são sustentadas por mecanismos de governança que são capazes de conter práticas oportunistas e, ao mesmo tempo, reduzir os custos de transação; e (vii) contratos mais flexíveis ou com um menor nível de especificações.

\section{Regime de quase-mercado}

Segundo Dyer, Cho e Chu (1998), as empresas podem empregar os relacionamentos tipo arm's length duráveis, denominados de quasemercado, para a aquisição de insumos que são necessários, mas não são estratégicos. Esses insumos não estratégicos geralmente diferem dos insumos estratégicos em duas dimensões chaves: na especificidade dos ativos (necessidade de investimentos específicos da relação) e no valor adicionado pelo componente. Os chamados insumos não estratégicos são padronizados, o que significa um baixo grau de interdependência entre comprador e fornecedor, bem como pouca necessidade de coordenação e, consequentemente, pouca necessidade de investimentos em ativos específicos da relação. Ademais, o valor adicionado pelos insumos não estratégicos é menor do que aquele adicionado pelos insumos estratégicos. 
Para a aquisição de insumos não estratégicos, tradicionalmente tem predominado o uso do regime arm's length. Entretanto, Dyer, Cho e Chu (1998) argumentam que existem três razões que diminuem a eficiência do regime arm's length:

- Os custos administrativos ou de transação associados com a gestão de um grande número de fornecedores tende a suplantar os benefícios.

- A divisão das compras entre múltiplos fornecedores reduz a habilidade destes para adquirir economias de escala significativas e não necessariamente leva a um maior poder de barganha do comprador.

- Pode-se gerar uma competição vigorosa entre poucos fornecedores (dois ou três), desde que sejam igualmente competentes e gerenciados de forma hábil.

Desse modo, o uso do regime de quase-mercado constitui uma abordagem superior ao regime tradicional (arm's length) para ser utilizado na aquisição de insumos não estratégicos, já que pode minimizar os custos de transação, permitir que os fornecedores obtenham ganhos de escala e manter uma vigorosa competição entre os fornecedores.

Consoante Bronzo (2004), a tendência observada nos últimos anos, em diferentes países e empresas, é que as estratégias de segmentação em regime de quase-mercado estão substituindo, aos poucos, os regimes anteriormente regulados de forma exclusiva pela perspectiva de mercado (arm's length).

Retomando a questão da importância de se pensar de forma estratégica as relações na cadeia de suprimento, Dyer, Cho e Chu (1998) apresentam uma comparação entre os regimes de quase-mercado e de parceria, no que diz respeito às situações nas quais cada um dos regimes deveriam ser utilizados. Assim sendo, o regime de parceria tende a ser o mais indicado:

- Em indústrias de produtos complexos, nas quais a demanda de complexidade aumenta o valor da coordenação efetiva entre as firmas. 
- Durante uma expansão econômica de longo prazo, na qual a escassez de recursos pode ser um problema.

- Quando o objetivo é a criação de valor de longo prazo, por exemplo, através da qualidade dos produtos e de novas tecnologias.

Por outro lado, a adoção do regime de quase-mercado pode ser mais desejável:

- Em indústrias que fabricam produtos simples ou indústrias com alto nível de padronização de componentes.

- Em indústrias em declínio, nas quais os fornecedores possuem excessos de capacidade crônicos, devido às barreiras de saída e aos altos custos fixos.

- Quando a redução de custos de curto prazo é o objetivo principal.

Essa visão da possibilidade e até mesmo da necessidade de se estabelecer tipos de relacionamentos e regimes diferentes, nas diferentes transações realizadas por uma organização em sua cadeia de suprimento, mostra-se relevante, tendo em vista que, em muitas cadeias de suprimento, pelas características dos produtos transacionados e do ambiente em que estão inseridas as firmas, é muito difícil se estabelecer regimes de parceria.

De acordo com Cox (2004), não existe uma maneira simples de gestão dos relacionamentos de negócio de um comprador que é apropriada em todas as circunstâncias. Os compradores necessitam de um guia de ação quando eles se confrontam com as circunstâncias do mundo real que ocorrem na gestão de suprimento e de fornecedores. Isso é chamado de apropriabilidade ou "a arte do possível". Os compradores normalmente possuem certo número de opções, ao invés de apenas uma, quando trabalham com fornecedores. Como resultado, é crítico que os compradores desenvolvam a competência para selecionar sabiamente entre um conjunto de opções de gestão de relacionamento nas decisões de compra.

Nos últimos anos, tem se desenvolvido uma visão ortodoxa de que a maneira mais apropriada para os compradores gerenciarem seus 
relacionamentos com fornecedores é evitando abordagens adversariais de curto prazo, em favor de relações mais transparentes, de longo prazo e colaborativas. Essas abordagens reforçam os benefícios de arranjos transparentes, confiáveis, de longo prazo, as chamadas relações "ganhaganha" (COX, 2004).

O que se percebe, entretanto, é que existem críticas à busca da utilização da abordagem supracitada por todas as empresas, em todos os relacionamentos interorganizacionais. Segundo Cox (2004), duas escolas de pensamento têm questionado o uso indiscriminado dessa abordagem pelos compradores. Primeiramente, existem aqueles que têm questionado se a abordagem de relações "ganha-ganha", colaborativas, de longo prazo, é realmente apropriada, já que, em alguns setores produtivos, devido às características de incerteza e variabilidade da demanda e do fornecimento, não é sempre possível utilizar os pressupostos dessa abordagem, ao contrário do que ocorre em setores como a indústria automobilística, por exemplo. Nesse caso, o uso de uma abordagem mais ágil e responsiva parece ser a mais apropriada.

\section{A Influência do ambiente institucional na vantagem competitiva}

As questões ligadas à localização e aos fatores institucionais são abordadas de forma conjunta por Porter (1991), por meio do relato de que a verdadeira origem da vantagem competitiva pode estar no ambiente local no qual a firma está baseada. As empresas criam e sustentam vantagem competitiva devido à capacidade de continuamente melhorar, inovar e aumentar suas vantagens competitivas ao longo do tempo, sob influência dos ambientes nas quais estão inseridas. Desse modo, existem fatores associados ao local em que uma firma opera que podem influenciar o valor dos seus recursos e, consequentemente, sua vantagem competitiva.

A consideração de que o ambiente institucional influencia a vantagem competitiva é reforçada por Oliver (1996). Na visão de Oliver (1996), as diferenças sustentáveis entre as firmas, bem como os retornos 
acima do normal, não são somente uma função das capacidades e habilidades da firma, nem das características do mercado e da indústria. As causas das ineficiências do mercado e da heterogeneidade das firmas são tanto econômicas como institucionais. Dessa forma, a habilidade de uma firma em desenvolver uma vantagem competitiva deriva não somente de suas respostas estratégicas às características do mercado, mas também de sua habilidade para explorar a distribuição irregular de informação, recursos, legitimidade e custos de transação que resultam dos impedimentos institucionais à eficiência do mercado.

Oliver (1996) propõe que a imersão social das firmas e mercados em um contexto institucional tem um impacto profundo sobre as diferenças entre as firmas. Nesse caso, a imersão social é definida como o alojamento das atividades econômica e estratégicas dentro de um ambiente institucional, o qual, por sua vez, refere-se ao contexto social e normativo que cerca as firmas e os mercados, em particular àquelas influências externas que definem o comportamento econômico socialmente aceito. Esse contexto social inclui o governo, os grupos de interesse, a opinião pública e as redes social, de negócios e profissional. A análise das relações existentes entre os recursos possuídos pela firma e o contexto institucional na qual esta está inserida apresenta-se como um campo de pesquisa bastante promissor (FAHY, 2000).

As diferenças sustentáveis entre as firmas são causadas, além de pelas questões relacionadas às firmas e aos mercados, também pela variação em: (a) como as firmas constroem socialmente os seus ambientes; (b) o grau de conectividade entre a firma e o seu ambiente institucional; (c) a extensão pela qual as firmas obedecem às regras e normas sociais; (d) a legitimidade conferida às firmas pelo ambiente institucional; (e) o conhecimento das firmas sobre as regras institucionais que governam seus comportamentos; e (f) a extensão pela qual as restrições institucionais limitam o alcance das opções estratégicas das firmas (OLIVER, 1996).

Assim sendo, Oliver (1996) sustenta que as influências institucionais constituem a fonte dos impedimentos institucionais 
para a eficiência do mercado, exercendo um papel vital na origem da heterogeneidade das firmas. Esses impedimentos institucionais para a eficiência das atividades do mercado causam as chamadas falhas de mercado e operam sobre a heterogeneidade das firmas primariamente através de três mecanismos: os custos de transação, o capital social e os custos cognitivos irrecuperáveis (cognitive sunk costs). O capital social constitui um recurso estratégico distribuído pelo ambiente institucional, que significa a credibilidade e a legitimidade de uma firma, as quais, por sua vez, ajudam a empresa na obtenção de tratamento preferencial, vantagem competitiva através de diferenciação e acesso facilitado a recursos. Desse modo, o capital social constitui uma importante fonte de diferenças sustentáveis entre as firmas e retornos econômicos diferentes.

O capital social cria um ambiente de confiança e reciprocidade que reduz os custos de transação e facilita a tomada de ações coletivas. Consequentemente, o capital social pode potencialmente contribuir para a eficiência das firmas e das aglomerações produtivas, bem como para melhorias associadas à transferência de conhecimento e à difusão de inovações (FENSTERSEIFER, 2009).

A influência do ambiente institucional na vantagem competitiva também é discutida por Bandeira-de-Mello (2007), que considera que a heterogeneidade de desempenho de firmas domésticas em economias emergentes, tais como a do Brasil, e a consequente possibilidade de obtenção de vantagem competitiva, é função da efetividade dessas firmas na gestão da dependência de recursos dos stakeholders. Considera-se, aqui, que essa questão é ainda mais crítica quando as firmas atuam em setores produtivos que são altamente dependentes de subsídios e incentivos governamentais para a manutenção de suas operações produtivas.

Em função do exposto, o ambiente institucional constitui uma das unidades de análise do modelo proposto, o qual é apresentado no tópico seguinte. 


\section{Modelo de análise}

Levando-se em consideração os aspectos discutidos nos tópicos anteriores, percebe-se que, apesar de ainda haver pouco consenso nas bases teóricas e metodológicas aplicadas ao estudo do SCM, alguns esforços estão sendo realizados no meio acadêmico, para trazer novas abordagens teóricas para esse campo de estudo. Entretanto, Halldorsson et al. (2007) acreditam que existe a carência de uma base teórica socioeconômica que pode ser utilizada para explanar e entender o arranjo interorganizacional proposto pelo SCM. A partir dessa constatação, presume-se a necessidade de se utilizar teorias organizacionais como suporte teórico para a gestão da cadeia de suprimento.

Para a formulação do modelo de análise, os principais aspectos teóricos considerados foram os construtos relacionados ao SCM, que permitem a investigação de quais aspectos do conceito de SCM são aplicados nas relações estabelecidas entre as empresas a serem investigadas e seus parceiros na cadeia de suprimento, bem como os pressupostos da teoria baseada em recursos, com foco principal na visão relacional, tendo em vista que, considerando-se as correntes explicativas da vantagem competitiva apresentadas no tópico 2 , busca-se permitir a análise da contribuição do SCM para a obtenção de vantagem competitiva baseada em recursos relacionais, embora a análise esteja aberta também à descoberta de outras possíveis explicações para a obtenção de vantagem competitiva por parte das organizações a serem investigadas.

É importante ressaltar que o modelo não contempla o construto vantagem competitiva, pois considera esse construto a priori, ou seja, a aplicação do modelo em estudos empíricos aplica-se a empresas que sejam reconhecidas como possuidoras de vantagem competitiva sobre seus concorrentes, seja por sua participação no mercado, seu desempenho financeiro (faturamento, lucratividade etc.), ou qualquer outro parâmetro utilizado para mensurar a vantagem competitiva. 
Na formulação do modelo foi considerado um escopo mais amplo da cadeia de suprimento, incluindo atores que podem, de alguma forma, influenciar o desempenho da cadeia e de suas empresas constituintes. Assim sendo, foram incluídos os prestadores de serviços logísticos, as instituições de fomento e o governo (em seus diversos níveis), de modo que as características do ambiente institucional possam ser consideradas na análise.

Feitas essas considerações, apresenta-se na Figura 1 o modelo de análise, na qual pode ser percebido o escopo da cadeia de suprimento considerado. Essa visão de cadeia de suprimento é baseada no trabalho de Lambert, Cooper e Pagh (1998), que denominam o núcleo principal de "empresa focal", visão esta que pode ser estendida a vários níveis de fornecedores e clientes, até o esgotamento de todos os entes participantes da cadeia de suprimento cujas análises sejam consideradas relevantes.

Figura 1 - Modelo de Análise

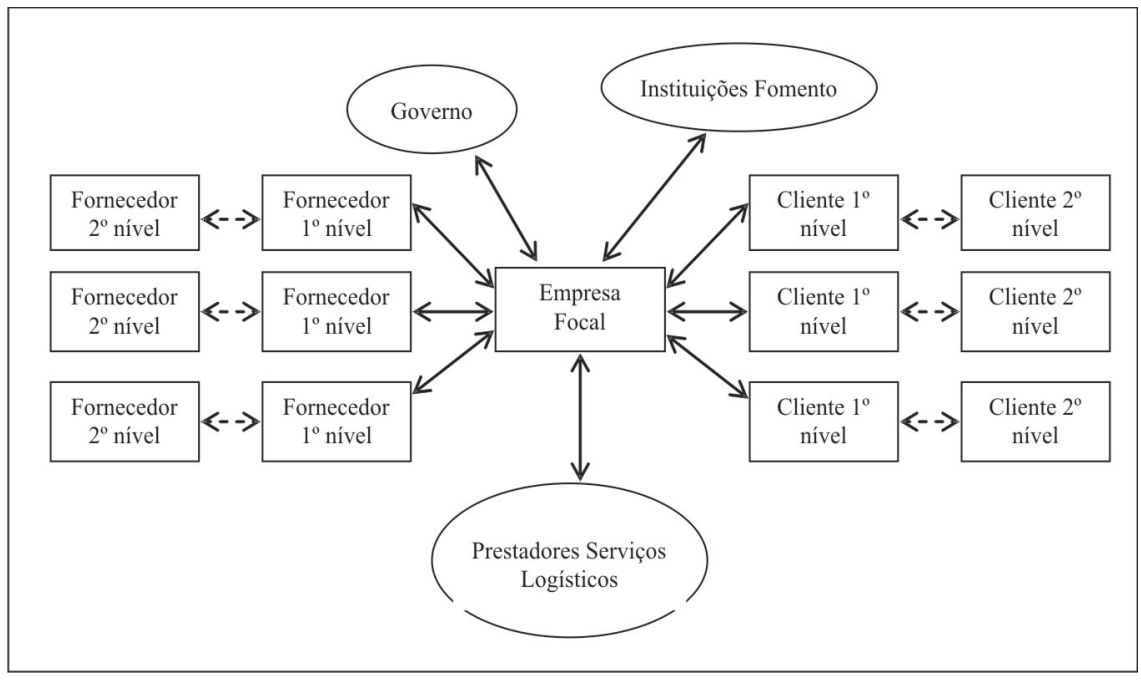

Fonte: Elaboração dos autores.

Nesse escopo considerado, o foco da análise é constituído pelas relações representadas pelas setas contínuas. Além de se analisarem 
as características dos recursos de propriedade das firmas do núcleo principal, bem como as relações entre as empresas que constituem a cadeia propriamente dita, ou seja, aquelas que realizam operações sucessivas que agregam valor ao produto que está sendo processado (fornecedores de $1^{\circ}$ nível, núcleo principal e clientes de $1^{\circ}$ nível), também é importante analisar como essas empresas estabelecem relações com o governo, as instituições de fomento e os prestadores de serviços logísticos; o intuito é verificar como essas relações contribuem para a vantagem competitiva das empresas investigadas, considerando-se a priori que as empresas possuem vantagem competitiva em relação aos seus concorrentes. Evidentemente, caso seja conveniente, a análise pode ser estendida aos demais componentes da cadeia de suprimento (fornecedores e clientes de $2^{\circ}$ nível, por exemplo) e às suas relações interorganizacionais.

As empresas focais são aquelas que representam de forma mais relevante as cadeias de suprimento a das quais fazem parte e que serão objeto de investigação com o uso do modelo.

Considerando o escopo da TBR utilizado no presente trabalho, o modelo de análise permite a verificação de como se configuram os recursos internos das empresas focais, bem como, do ponto de vista das empresas, de que modo esses recursos contribuem para a vantagem competitiva. O conjunto de recursos internos a serem analisados leva em consideração os pressupostos da RBV (BARNEY, 1991; WERNERFELT, 1984;) e da KBV (GRANT, 1996; KOGUT; ZANDER, 1992), ressaltandose a relevância a ser dada, na análise, à geração, aplicação e difusão do conhecimento no âmbito das empresas.

Já que o foco principal é avaliar a contribuição do SCM para a vantagem competitiva, é importante que seja dada maior ênfase à análise dos recursos relacionais, conforme definidos na visão relacional (DYER; SINGH, 1998), ou seja, aqueles que são compartilhados pelas empresas em seus relacionamentos interorganizacionais no âmbito do escopo considerado da cadeia de suprimento. Da mesma forma, o modelo prevê a análise das relações da empresa focal da cadeia de suprimento com 
componentes do ambiente institucional que, de alguma forma, podem influenciar o desempenho das empresas da cadeia em relação a seus concorrentes em âmbito global. Cada um dos componentes do ambiente institucional considerados pode influenciar a aquisição e manutenção de recursos que, por sua vez, podem contribuir para a formação de vantagem competitiva na cadeia de suprimento:

- Instituições de fomento $\rightarrow$ Podem permitir a aquisição de recursos financeiros, tanto para investimento como para capital de giro, os quais, dependendo das condições de aquisição (taxas de juros, prazos etc.), podem trazer ou não vantagens relativas da cadeia de suprimento analisada sobre seus concorrentes em âmbito nacional e global;

- Governo $\rightarrow$ No ambiente contemporâneo de competitividade global, especialmente em economias emergentes, os governos podem influenciar o desempenho e a competitividade empresarial, ao deliberar sobre concessão de subsídios e incentivos fiscais, taxa básica de juros, câmbio, barreiras tarifárias e não tarifárias, entre outras questões. Da mesma forma, o governo possui papel crucial na definição das regras do mercado, bem como no cumprimento dessas regras, a partir do estabelecimento de instituições reguladoras e jurídicas fortes. A maneira como as empresas da cadeia de suprimento, atuando de forma isolada ou em conjunto, através de suas entidades de classe, se relacionam com os diversos níveis de governo e podem influenciar as suas deliberações, constitui um importante foco de análise para a formação de vantagem competitiva.

Com relação aos prestadores de serviços logísticos, que constituem organizações que permitem às empresas de uma cadeia de suprimento, caso isso seja desejado, a terceirização das diversas etapas do processo logístico (armazenagem, manuseio de materiais, gestão de estoques, transporte), torna-se interessante avaliar, para as empresas que se pretende analisar com o uso do modelo, se existem prestadores de serviços logísticos atuando, bem como a maneira como estes se relacionam com as empresas que fazem parte do escopo de análise. Observa-se que, em muitas situações, para entender as necessidades 
operacionais de determinada cadeia de suprimento, os prestadores de serviços logísticos necessitam desenvolver recursos específicos, em conjunto com as empresas para as quais prestam serviços, os quais podem ser considerados recursos relacionais.

Nas análises a serem efetuadas com o uso do modelo, para a definição das variáveis, utiliza-se como referência os elementos que se supõe contribuírem para a obtenção de vantagem competitiva, conforme os pressupostos da TBR (ACEDO; BARROSO; GALLAN, 2006; BARNEY, 1991; DYER; SINGH, 1998; GRANT, 1991; GRANT, 1996; GALLAN, 2006; KOGUT; ZANDER, 1992), bem como os construtos relacionados ao SCM (BURGESS; SINGH; KOROGLU, 2006; CHEN; PAULRAJ, 2004; MENTZER et al., 2001) que têm impacto potencial sobre o desempenho das firmas e, consequentemente, podem contribuir para a obtenção de vantagem competitiva. Ademais, a investigação acerca das estruturas de governança (WILLIAMSOM, 1991) predominantes e dos regimes relacionais (DYER; CHO; CHU, 1998) presentes na cadeia de suprimento também são objetos de análise do modelo. Então, podem ser definidas as seguintes variáveis a serem investigadas:

- Recursos (financeiros, humanos, tecnológicos, materiais, de conhecimento) das firmas focais e suas características.

- Estruturas de governança predominantes e localização dos principais atores que compõem as cadeias de suprimento estudadas, considerando o escopo definido pelo modelo de análise.

- Regimes relacionais presentes nos relacionamentos interorganizacionais a serem analisados, considerando-se também os relacionamentos com os prestadores de serviços logísticos: regime de mercado (arm's length), regime de parceria ou regime de quasemercado.

- Investimentos em ativos específicos das relações e recursos relacionais presentes nas relações das empresas estudadas. 
- Mecanismos de troca de informações e de conhecimentos utilizados nas relações entre as empresas pesquisadas, incluindo os recursos desenvolvidos para permitir as trocas;

- Combinações de recursos, capacidades ou habilidades complementares nas relações interorganizacionais investigadas, incluindo a coordenação entre equipes das empresas envolvidas nas relações em processos de desenvolvimento de produtos, produção e logística.

- Ganhos relacionais e formas de apropriação desses ganhos entre os componentes das relações interorganizacionais investigadas.

- Mecanismos de preservação dos ganhos relacionais associados às relações interorganizacionais das empresas estudadas.

No que diz respeito à influência do ambiente institucional em relação ao governo e às instituições de fomento, o uso do modelo deve permitir a identificação de possíveis elementos que, do ponto de vista das empresas, em suas relações com essas entidades, trazem algum tipo de vantagem competitiva. Por exemplo, nas relações das empresas com o governo, se existem subsídios ou incentivos fiscais de qualquer tipo; nas relações com as instituições de fomento, deve-se focar o acesso aos recursos financeiros, investigando-se quais os instrumentos creditícios existentes que são considerados vantajosos.

De forma resumida, pode-se afirmar que o modelo proposto permite analisar como o SCM contribui para a vantagem competitiva das empresas focais, estando a análise subdividida em três níveis, conforme mostrado no Quadro 2. 
Quadro 2 - Modelo de análise

\begin{tabular}{|c|c|c|c|}
\hline Nível de Análise & Unidade de Análise & Foco da Análise & Objetivo da Análise \\
\hline 1. Intraorganizacional & $\begin{array}{l}\text { - Firmas individuais } \\
\text { que formam o núcleo } \\
\text { principal de análise. }\end{array}$ & $\begin{array}{l}\text { - Recursos } \\
\text { financeiros. } \\
\text { - Recursos } \\
\text { humanos. } \\
\text { - Recursos } \\
\text { tecnológicos. } \\
\text { - Recursos } \\
\text { materiais. } \\
\text { - Recursos de } \\
\text { conhecimento. }\end{array}$ & $\begin{array}{l}\text { - Características dos } \\
\text { recursos. } \\
\text { - Contribuição dos } \\
\text { recursos para a } \\
\text { obtenção de rendas } \\
\text { acima do normal } \\
\text { e a obtenção } \\
\text { de vantagem } \\
\text { competitiva. }\end{array}$ \\
\hline 2. Interorganizacional & $\begin{array}{l}\text { - Relações } \\
\text { interorganizacionais } \\
\text { das firmas da cadeia } \\
\text { de suprimento e } \\
\text { destas com os } \\
\text { prestadores de } \\
\text { serviços logísticos. }\end{array}$ & $\begin{array}{l}\text { - Tipos de } \\
\text { relações } \\
\text { estabelecidas. } \\
\text { - Recursos } \\
\text { relacionais. }\end{array}$ & $\begin{array}{l}\text { - Caracterizar os } \\
\text { tipos de relações } \\
\text { interorganizacionais } \\
\text { Identificar } \\
\text { investimentos em } \\
\text { ativos específicos e } \\
\text { recursos relacionais. } \\
\text { - Avaliar troca de } \\
\text { informações e de } \\
\text { conhecimento, } \\
\text { combinação } \\
\text { de recursos, } \\
\text { capacidade e } \\
\text { habilidades nas } \\
\text { relações. } \\
\text { - Identificar ganhos } \\
\text { relacionais e } \\
\text { mecanismos de } \\
\text { preservação }\end{array}$ \\
\hline $\begin{array}{l}\text { 3. Ambiente } \\
\text { Institucional }\end{array}$ & $\begin{array}{l}\text { - Relações das } \\
\text { empresas da cadeia } \\
\text { de suprimento } \\
\text { com componentes } \\
\text { do ambiente } \\
\text { institucional. }\end{array}$ & $\begin{array}{l}\text { - Instituições de } \\
\text { fomento. } \\
\text { - Governo. }\end{array}$ & $\begin{array}{l}\text { - Avaliar a influência } \\
\text { dessas relações no } \\
\text { acesso a recursos } \\
\text { e na obtenção } \\
\text { de vantagem } \\
\text { competitiva; }\end{array}$ \\
\hline
\end{tabular}

Fonte: Elaboração dos autores.

O primeiro nível de análise (intraorganizacional) permite a avaliação da contribuição dos recursos internos (financeiros, humanos, tecnológicos, materiais, de conhecimento) das firmas focais para a vantagem competitiva. Esse nível de análise não está relacionado ao objetivo geral do trabalho, por isso não está destacado (em cinza) no quadro. 
O segundo nível de análise (interorganizacional) permite a caracterização dos tipos de relacionamentos organizacionais e a avaliação da contribuição destes e dos recursos relacionais para a vantagem competitiva. Por sua vez, o terceiro nível de análise (ambiente institucional) permite a avaliação da contribuição dos componentes do ambiente institucional (governo e instituições de fomento) para a vantagem competitiva. Assim sendo, o segundo e o terceiro níveis de análise são aqueles que permitem a análise da contribuição do SCM para a vantagem competitiva, considerando o escopo ampliado da cadeia de suprimento, que inclui o ambiente institucional e, portanto, merecem destaque no quadro e constituem os elementos diferenciais do modelo de análise, pois podem permitir a realização de estudos empíricos futuros em cadeias de suprimento industriais, com instrumentos de pesquisa que contemplem as variáveis anteriormente citadas e que possibilitem a análise da contribuição do SCM para a vantagem competitiva.

\section{Considerações finais}

Esse ensaio teórico teve como objetivo a elaboração de um modelo de análise que permita avaliar como a gestão da cadeia de suprimento contribui para a obtenção de vantagem competitiva pelas empresas, com aplicação direcionada a cadeias de suprimento industriais. A partir do objetivo traçado, discorreu-se sobre o referencial teórico relacionado à questão da vantagem competitiva, à teoria baseada em recursos, à gestão da cadeia de suprimento, aos relacionamentos interorganizacionais na cadeia de suprimento e à influência do ambiente institucional na vantagem competitiva.

Considerando-se as diferentes correntes teóricas explicativas da vantagem competitiva (VASCONCELOS; CYRINO, 2000), a propagada ideia de que a gestão da cadeia de suprimento constitui importante elemento que pode favorecer a obtenção de vantagem competitiva por parte das empresas que seguem seus pressupostos (CHEN; PAULRAJ, 2004), a necessidade de melhor desenvolvimento teórico do SCM (BURGESS; SINGH; KOROGLU, 2006; MIGUEL; BRITO, 2008) 
e a pertinência se utilizar teorias organizacionais como suporte teórico à gestão da cadeia de suprimento (HALLDORSSON et al., 2007), percebeu-se ser adequada a utilização da teoria baseada em recursos (ACEDO; BARROSO; GALAN, 2006) para a formatação do modelo de análise, especialmente no que tange à Visão Relacional (DYER; SINGH, 1998), já que o foco principal do modelo é permitir a análise da contribuição do SCM para a obtenção de vantagem competitiva, a partir da análise das relações interorganizacionais. Ademais, relatouse a necessidade de inclusão do ambiente institucional, a partir dos argumentos de estudos anteriores (BANDEIRA-DE-MELLO, 2007; FAHY, 2000; OLIVER, 1996), no escopo da cadeia de suprimento, tendo em vista a influência dos fatores institucionais na heterogeneidade das firmas e, consequentemente, na vantagem competitiva.

De modo geral, percebe-se que o modelo de análise proposto permitirá a realização de estudos empíricos, quaisquer que sejam as abordagens utilizadas (quantitativa, qualitativa ou mista), os quais, assim como o próprio modelo, poderão contribuir para a inclusão de novos elementos e o fortalecimento do "núcleo" teórico do campo de conhecimento da Gestão da Cadeia de Suprimento, considerando-se aqui o conceito de núcleo apresentado por Lakatos (1979).

Assim sendo, podem ser destacadas as principais contribuições teóricas desse trabalho: (1) utilização da teoria baseada em recursos, incluído a RBV a KBV e a visão relacional como suporte teórico para a análise da contribuição do SCM para a vantagem competitiva de empresas focais de cadeias de suprimento industriais; (2) argumentação teórica e incorporação do ambiente institucional no escopo da cadeia de suprimento, de modo que se possa avaliar a contribuição de seus componentes para a vantagem competitiva; (3) desenvolvimento de um modelo de análise e definição de variáveis que permitem o desenvolvimento de instrumentos de pesquisa e a realização de estudos empíricos futuros com o objetivo de analisar a contribuição do SCM para a vantagem competitiva de empresas focais de cadeias de suprimento industriais. 
A partir do modelo de análise desenvolvido, pretende-se desenvolver no futuro próximo instrumentos de pesquisa que permitam a realização de estudos empíricos em diferentes cadeias de suprimento industriais, tanto de cunho qualitativo como de abordagem quantitativa ou mista.

\section{Referências}

ACEDO, F. J.; BARROSO, C.; GALAN, J. L. The resource-based theory: dissemination and main trends. Strategic Management Journal, , v. 27, n. 7, p. 621-636, July 2006.

BANDEIRA-DE-MELLO, R. External dependencies, relational resources and performance heterogeneity in emerging economies. In: ENCONTRO DAASSOCIAÇÃO NACIONAL DE PÓS-GRADUAÇÃO EM ADMINISTRAÇÃO, 31, 2007, Rio de Janeiro. Anais... Rio de Janeiro: ANPAD, 2007.

BARNEY, J. Firm resources and sustained competitive advantage. Journal of Management, v. 17, n. 1, p. 99-120, Mar. 1991.

BARNEY, J. B; HANSEN, M. H. Trustworthiness as a source of competitive advantage. Strategic Management Journal, v. 15, n. S1, p. 175-190, Winter 1994.

BARNEY, J. B.; HESTERLY, W. S. Administração estratégica e vantagem competitiva. São Paulo: Pearson Prentice Hall, 2007.

BRITO, L. A. L.; VASCONCELOS, F. C. A heterogeneidade do desempenho, suas causas e o conceito de vantagem competitiva: proposta de uma métrica. Revista de Administração Contemporânea, Curitiba, v. 8, n. Especial, p. 107-129, 2004.

BRONZO, M. Relacionamentos colaborativos em redes de suprimento. Revista de Administração de Empresas, Minas Gerais, Edição Especial, v. 44, p. 61-73, abr-dez, 2004. 
BURGESS, K.; SINGH, P. J.; KOROGLU, R. Supply chain management: a structured literature review and implications for future research. International Journal of Operations and Production Management, v. 26, n. 7, p. 703-729, July 2006.

CAVES, R.E. Economic analysis and the quest for competitive advantage. American Economic Review, v. 74, n. 2, p. 127-132, May 1984.

CHEN, I. J.; PAULRAJ, A. Towards a theory of supply chain management: the constructs and measurements. Journal of Operations Management, v. 22, n. 2, p. 119-150, April 2004.

COOL, K.; COSTA, L. A.; DIERICKX, I. Constructing competitive advantage. In: PETTIGREW, A.; THOMAS, H.; WHITTINGTON, R. Handbook of strategic management. London: Sage Publications, 2002, Cap. 3, p. 55-71.

COUSINS, P. D.; LAWSON, B.; SQUIRE, B. Supply chain management: theory and practice - the emergence of an academic discipline? International Journal of Operations and Production Management, v. 26, n. 7, p. 697-702, July 2006.

COX, A. The art of the possible: relationship management in power regimes and supply chains. Supply Chain Management: An International Journal, v. 9, n. 5, p. 346-356, 2004.

DYER, J. H. Specialized supplier networks as a source of competitive advantage: evidence from the auto industry. Strategic Management Journal, v. 17, n. 4, p. 271-291, April 1996.

. Effective interfirm collaboration: how firms minimize transaction costs and maximize transaction value. Strategic Management Journal, v. 18, n. 7, p. 535-556, August 1997.

DYER, J. H.; CHO, D. S.; CHU, W. Strategic supplier segmentation: the next "best practice" in supply chain management. California Management Review, v. 40, n. 2, p. 57-77, Winter 1998. 
DYER, J. H.; SINGH, H. The relational view: cooperative strategy and sources of inter-organizational competitive advantage. Academy of Management Review, v. 23, n. 4, p. 660-679, October 1998.

FAHY, J. The resource-based view of the firm: some stumbling-blocks on the road to understanding sustainable competitive advantage. Journal of European Industrial Training, v. 24, n. 2/3/4, p. 94-105, 2000.

FENSTERSEIFER, J. E. Strategic resources and sustainability of competitive advantages in industrial clusters: towards a general analytical framework. In: ENCONTRO DA ASSOCIAÇÃO NACIONAL DE PÓS-GRADUAÇÃO EM ADMINISTRAÇÃO, 33, 2009, São Paulo. Anais... Rio de Janeiro: ANPAD, 2009. CD-ROM

GHEMAWAT, P. Sustainable advantage. Harvard Business Review, v. 64, n. 5, p. 53-58, September 1986.

GRANT, R. M. The resource-based theory of competitive advantage: implications for strategy formulation. California Management Review, v. 33, n. 3, p. 114-135, Spring 1991.

GRANT, R. M. Toward a knowledge-based theory of the firm. Strategic Management Journal, v. 17, n. S2, p. 109-122, Winter 1996.

HILL, C. W. L. Cooperation, opportunism and the invisible hand: implications for transaction cost theory. The Academy of Management Review, v. 15, n. 3, p. 500-513, July 1990.

KOGUT, B.; ZANDER, U. Knowledge of the firm, combinative capacities and the replication of technology. Organization Science, v. 3, n. 3, p. 383-397, August 1992.

HALLDORSSON, A.; KOTZAB, H.; MIKKOLA, J. H.; LARSEN-SKJOTT, T. Complementary theories to supply chain management. Supply Chain Management: An International Journal, v. 12, n. 4, p. 284-296, 2007.

LAKATOS, I. O falseamento e a metodologia dos programas de pesquisa científica. In: LAKATOS, I.; MUSGRAVE, A. (orgs.) A crítica 
e o desenvolvimento do conhecimento. São Paulo: Cultrix, 1979, p. 109-243.

LAMBERT, D. M.; COOPER, M. C.; PAGH, J. Supply chain management: implementation issues and research opportunities. The International Journal of Logistics Management, v. 9, n. 2, p. 1-19, 1998.

McGAHAN, A. M.; PORTER, M. E. How much does industry matter, really? Strategic Management Journal, v. 18, n. S1, p. 15-30, July 1997.

MENTZER, J. T. et al. Defining supply chain management. Journal of Business Logistics, v. 22, n. 2, p. 1-25, Autumn 2001.

MIGUEL, P. L. de S.; BRITO, L. A. L. Gestão da cadeia de suprimento e o impacto no desempenho operacional: um estudo empírico no Brasil. In: ENCONTRO DAASSOCIAÇÃO NACIONAL DE PÓS-GRADUAÇÃO EM ADMINISTRAÇÃO, 32, 2008, Rio de Janeiro. Anais... Rio de Janeiro: ANPAD, 2008. CD-ROM.

OLIVER, C. Determinants of interorganizational relationships: integration and future directions. The Academy of Management Review, v. 15, n. 2, p. 241-265, April 1990.

OLIVER, C. The institutional embeddedness of economic activity. Advances in Strategic Management, v. 13,p. 163-186, 1996.

PETERAF, M. A. The cornestones of competitive advantage: a resourcebased view. Strategic Management Journal, v. 14, n. 3, p. 179-191, March 1993.

PORTER, M. E. Estratégia competitiva: técnicas para análise de indústrias e da concorrência. 7. ed. Rio de Janeiro: Campus, 1986.

. Vantagem competitiva: criando e sustentando um desempenho superior. 27. ed. Rio de Janeiro: Elsevier, 1989.

Towards a dynamic theory of strategy. Strategic Management Journal, v. 12, n. S2, p. 95-117, Winter 1991. 
RUMELT, R. P. How much does industry matter? Strategic Management Journal, v. 12, n. 3, p. 167-185, March 1991.

SCHMALENSEE, R. Do markets differ much? The American Economic Review, v. 75, n. 3, p. 341-351, June 1985.

THORELLI, H. B. Networks: between markets and hierarchies. Strategic Management Journal, v. 7, n. 1, p. 37-51, January/February 1986.

UZZI, B. Social structure and competition in interfirm networks: the paradox of embeddedness. Administrative Science Quarterly, v. 42, n. 1, p. 35-67, March 1997.

VASCONCELOS, F. C.; BRITO, L. A. L. Vantagem competitiva: o construto e a métrica. Revista de Administração de Empresas, São Paulo, v. 44, n. 2, p. 51-63, Mai./Jul. 2004.

VASCONCELOS, F. C.; CYRINO, A. B. Vantagem competitiva: os modelos teóricos atuais e a convergência entre estratégia e teoria organizacional. Revista de Administração de Empresas, São Paulo, v. 40, n. 4, p. 20-37, Out./Dez. 2000.

WERNERFELT, B. A resource-based view of the firm. Strategic Management Journal, v. 5, n. 2, p. 171-180, April/June 1984.

WILLIAMSOM, O. E. Markets and hierarquies: analysis and antritust implications. London: The Free Press, 1975.

. Las instituciones económicas del capitalismo. México: Fondo de Cultura Económica, 1989.

. Comparative economic organization: the analysis of discrete structural alternatives. Administrative science quarterly, v. 36, n. 2, p. 269-296, June 1991.

The mechanisms of governance. Oxford: Oxford University Press, 1996. 
. The theory of the firm as governance structure: from choice to contract. Journal of Economic Perspectives, v. 16, n. 3, p. 171-195, Summer 2002.

. The economics of governance. The American Economic Review, v. 95, n. 2, p. 1-18, May 2005.

Artigo recebido em: 12/08/2013

Aprovado em: 07/05/2014 